\title{
The trade-off between foraging activity and predation risk for Rana temporaria in different food environments
}

\author{
Peter Eklöv and Charlotta Halvarsson
}

\begin{abstract}
We evaluated the trade-off between foraging activity and predation risk for larvae of an anuran species presented with different types of food resources. In the laboratory we examined the effects of benthic and phytoplankton resources and the two types combined on the activity and mortality of larvae of the common frog, Rana temporaria, exposed to predatory larva, Dytiscus marginalis. Predation mortality of tadpoles increased with the duration of the experiment and was highest in the presence of the phytoplankton resource alone. This was explained by a decrease in prey activity in the benthic- and combined-resource treatments when the predator was present, whereas in the phytoplankton treatment, the activity of the tadpoles were similar in the presence or absence of the predator. In the presence of the predator, prey mainly used the bottom of the aquarium in the benthic- and combined-resource treatments. In contrast, in the phytoplankton treatment they used the water column more than in the other treatments. In the presence of the predator, the prey had a lower consumption rate in the phytoplankton treatment than in the other treatments. Predator activity did not change among treatments. The results suggest that the trade-off between foraging activity and predation mortality for anuran larvae is strongly affected by the types of food resources present in the environment.
\end{abstract}

Résumé : Nous avons évalué le compromis que font les larves d'anoures entre leur activité de recherche de nourriture et le risque de prédation lorsqu'elle sont mises devant un choix de ressources alimentaires. Au cours d'une expérience en laboratoire, nous avons examiné les effets du benthos et du phytoplancton et les effets des deux ressources combinées sur l'activité et la mortalité des larves de la grenouille Rana temporaria exposées à des larves prédatrices létales et non létales de Dytiscus marginalis. La mortalité des têtards par prédation augmentait avec la durée de l'expérience et elle s'est avérée maximale en présence du phytoplancton. Cela peut s'expliquer par le fait que l'activité des proies en présence d'un prédateur est réduite dans le benthos ou quand les deux ressources sont combinées, alors que, dans le phytoplancton, l'activité des têtards ne change pas, avec ou sans prédateurs. En présence d'un prédateur, les proies se tenaient surtout au fond de l'aquarium dans les expériences avec benthos ou avec les deux ressources combinées. En revanche, dans l'expérience en présence de phytoplancton seulement, les têtards utilisaient davantage la colonne d'eau. En présence de prédateurs, les proies avaient un taux de consommation moins élevé dans le traitement au phytoplancton que dans les autres traitements. L'activité des prédateurs n'était pas modifiée par les traitements. Les résultats semblent indiquer que l'équilibre entre l'activité de recherche de nourriture et les risques de prédation chez les larves d'anoures est fortement affecté par le type de ressource alimentaire offert par le milieu.

[Traduit par la Rédaction]

\section{Introduction}

Foraging is a risky activity because when individuals search for food they expose themselves to a higher risk of being detected by predators. Many animals can assess the relative risk of starving or being killed by predators and they adjust their behavior to minimize the risk. Searching for food and avoiding predators is one of the most important conflicts in an animal's life, and both theoretical and experimental studies have confirmed this (Milinski and Heller 1978; Abrams 1984; Werner and Gilliam 1984; McNamara

Received October 12, 1999. Accepted December 9, 1999.

P. Eklöv ${ }^{1}$ and C. Halvarsson. Animal Ecology, Department of Ecology and Environmental Science, Umeå University, S-901 87 Umeå, Sweden.

${ }^{1}$ Author to whom all correspondence should be addressed (e-mail: Peter.Eklöv@eg.umu.se). and Houston 1987; Anholt and Werner 1995; Werner and Anholt 1996). Models that trade off mortality risk against resource acquisition predict a reduction in activity when mortality risk increases (McNamara and Houston 1987, 1994; Abrams 1993; Werner and Anholt 1993). Werner and Anholt (1993) showed that if mortality risk depends on foraging activity, then foraging activity should decrease at higher food levels. Anholt and Werner (1995) verified this prediction experimentally by showing that predation mortality of bullfrog tadpoles decreased when activity decreased because of higher levels of food resources. However, because of the complexity of food resources that prey may encounter in the natural environment, we can expect the trade-off between predation risk and foraging activity or habitat choice to vary with habitat-specific quality and quantity of food (Peckarsky and Penton 1989; Kupferberg 1997b).

Larval anurans feed mainly by scraping attached algae or filtering phytoplankton, and the ability to exploit different food resources varies among taxa (Wassersug 1972; Kupferberg 1997a). Studies have shown that anuran larvae are able 
to switch between planktonic and benthic food resources (Sanderson and Kupferberg 1999). The ingestion rate of these food resources is species-specific, although anuran larvae in general seem to feed indiscriminately on planktonic food resources, whereas they feed selectively on benthic food resources (Viertel 1992; Kupferberg 1997b). Switches between habitats with different food resource levels are often driven by differences in predation risk between habitats because food resources are depleted at a higher rate at low-risk sites. Although tadpoles have been shown to avoid predators spatially (Werner 1992; Eklöv and Werner 2000), the major mechanism that may influence the trade-off between forage intake and predation risk for tadpoles seems to be changes in activity level rather than habitat use per se (Kupferberg 1997b).

The purpose of this study was to test how differences in profitability of food resources could create differences in food-intake rate and thus indirectly affect prey mortality by a resource-dependent change in the activity level of prey. We predicted that $(i)$ forage intake will be lower when a single food resource is present than when multiple food resources are present, if the single food resource is depleted, (ii) if the foraging activity, and consequently the food resource intake rate, changes with the food-resource level, then the activity level and also the predation rate should be higher in the presence of a single resource than in the presence of multiple food resources.

\section{Methods}

Eggs of the common frog were collected at Sand, southeast Umeå, and hatched in outdoor wading pools. The newly hatched tadpoles were fed a mixture of Tetramin fish flakes and rabbit chow ad libitum. After 3 weeks the diet was changed to a mixture of benthic and planktonic algae collected in a nearby pond and the tadpoles were continuously fed ad libitum until they reached the appropriate size for the experiment (see below). Dytiscus marginalis larvae were collected at Lill-Vitskärsdiket near Umeå 2 weeks before the experiment, held in cylindrical predator cages $(10 \mathrm{~cm}$ high and $12.5 \mathrm{~cm}$ wide) covered with fine-mesh screen $(1.6 \mathrm{~mm})$ in a larger pen, and fed common frog tadpoles ad libitum. All animals in this study were cared for according to the principles and guidelines of the Canadian Council on Animal Care.

The experiment was conducted in 40-L indoor aquaria filled with $30 \mathrm{~L}$ of tap water and furnished with cylindrical predator cages $(10 \mathrm{~cm}$ high and $12.5 \mathrm{~cm}$ wide) covered with fine-mesh screen $(1.6 \mathrm{~mm})$ and placed at the surface at one end of each aquarium. We employed a $2 \times 3$ fully factorial design with two predator treatments (nonlethal and lethal) and three resource treatments (benthic and phytoplankton resources and the two resource types combined). We used four replicates of each treatment combination randomly assigned to aquaria. Carex sp. stems were collected at a nearby pond and $24 \mathrm{~g}$ (wet mass) was added as the benthic resource to the aquaria $24 \mathrm{~h}$ before the experiment started. Water from a nearby lake was filtered through a $45-\mu \mathrm{m}$ filter. A growth medium, Substral, was added and cultured in daylight for 14 days. The cultured water was diluted to $887.67 \times 10^{4}$ particles $/ \mathrm{mL}$, which was calculated from functional-response experiments to achieve the maximum potential ingestion rate (Viertel 1992). The water was then used as the phytoplankton resource and was added to the aquaria assigned the phytoplankton and combined-resource treatments $4 \mathrm{~h}$ before the experiment started.
Five days before the start of the experiment, one dytiscid larva was transferred to each experimental aquarium. The predators were allowed to swim freely in the aquaria and fed four tadpoles a day before the experiment started. Two hours before the experiment started, the predators were placed in their cages and fed 10 common frog tadpoles. The experiment started when 12 tadpoles $(105 \pm 30 \mathrm{mg}$; mean $\pm 1 \mathrm{SD})$ were added to each aquarium. All tadpoles used in the experiment were drawn from the same pool. Twenty-four hours after the start of the experiment the phytoplankton resource was increased to the original particle concentration, based on Viertel (1992), the predators were released from their cages, and the experiment ran for another $24 \mathrm{~h}$.

Behavior was recorded 4, 24, and $28 \mathrm{~h}$ after the experiment started. Activity of the tadpoles and the predator were measured by counting all individuals that were moving every $30 \mathrm{~s}$ for $5 \mathrm{~min}$. At the same time the positions of the tadpoles and the predator in the aquarium (bottom, water column, or cage) were recorded. At the end of the experiment the aquaria were emptied and the surviving tadpoles counted.

The feeding efficiency of common frog tadpoles was estimated in a separate experiment immediately following that previously described. The same resource treatments as in the previous experiment were assigned to $40-\mathrm{L}$ aquaria. Predators were placed in their cages $24 \mathrm{~h}$ before the experiment started and fed 10 common frog tadpoles from the same pool as in the previous experiment $(105 \pm$ $30 \mathrm{mg}$ ). A colored band was induced in the gut by exposing the tadpoles to a liquid containing colored particles immediately before the experiment started. After $10 \mathrm{~min}, 12$ tadpoles were placed in the experimental aquaria and after $4 \mathrm{~h}, 4$ tadpoles from each aquarium were removed, anaesthetized in MS 222, and preserved in $10 \%$ formaldehyde for later gut analysis. Food consumption of tadpoles in the different treatments was estimated by measuring the length of the gut to the colored band.

Analyses of mortality and activity were carried out on mean proportions of each aquarium using ANOVA. Contrasts for multiple comparisons were analyzed using Tukey's post-hoc test. Predator habitat use was tested with the $G$ test. Data were arcsine- or ln$(x+1)$-transformed when necessary to stabilize the variance.

\section{Results}

\section{Prey mortality}

The mortality rate during the nonlethal part of the experiment was low $(\approx 1 \%)$. The predator caused some mortality of tadpoles by capturing them through the screen that covered the predator cage.

The mortality rate of tadpoles during the lethal part of the experiment increased with time and varied among resource treatments (Fig. 1, Table 1). Mortality was higher in the phytoplankton treatment than in the other treatments (Tukey's post-hoc test, phytoplankton versus combined-resource treatment, $P=0.013$; phytoplankton versus benthic-resource treatment, $P=0.013$, after $4 \mathrm{~h}$ ).

\section{Prey activity and spatial avoidance}

Prey activity levels strongly decreased in the presence of the predator in the combined- and benthic-resource treatments (Fig. 2, Table 2). In contrast, prey activity levels in the phytoplankton treatment were similar in the presence or absence of the predator, as indicated by the significant predator $\times$ resource interaction term (Fig. 2, Table 2). Tadpole activity levels were lower after $4 \mathrm{~h}$ in the presence of the non-lethal predator than after $4 \mathrm{~h}$ in the presence of the lethal predator (Fig. 2, Table 2). However, the lack of inter- 
Fig. 1. Proportions (mean $\pm 1 \mathrm{SE}$ ) of the initial number of common frog tadpoles killed by Dytiscus marginalis after 4 and $24 \mathrm{~h}$ in combined-, benthic-, and phytoplankton-resource treatments.

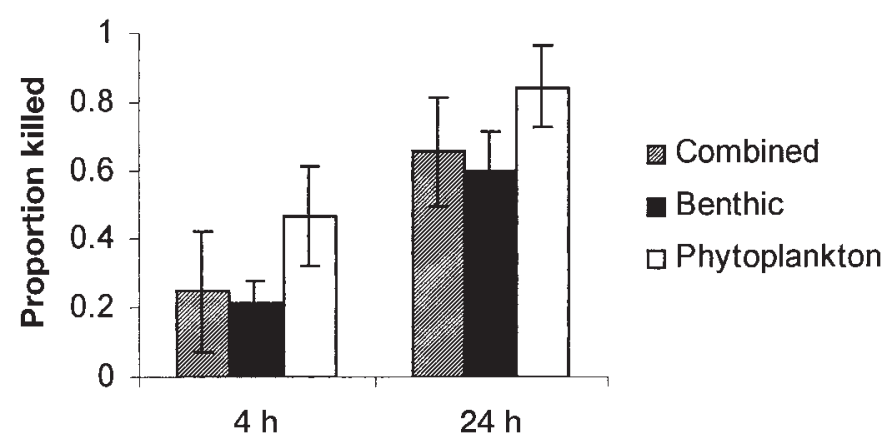

Table 1. Repeated-measures ANOVA of the effect of resource (combined, benthic, and phytoplankton) on predation mortality of common frog tadpoles.

\begin{tabular}{lllll}
\hline Source of variation & $\begin{array}{l}\text { Sum of } \\
\text { squares }\end{array}$ & df & $F$ & $P$ \\
\hline Between subjects & & & & \\
$\quad$ Resource & 1.209 & 2 & 6.753 & 0.016 \\
$\quad$ Error & 0.805 & 9 & & \\
$\quad$ Within subjects & & & & \\
$\quad$ Time & 3.049 & 1 & 30.969 & 0.000 \\
$\quad$ Time $\times$ resource & 0.144 & 2 & 0.729 & 0.509 \\
Error & 0.886 & 9 & & \\
\hline
\end{tabular}

Table 2. Repeated-measures ANOVA for the effect of predator and resource (combined, benthic, and phytoplankton) on activity levels of common frog tadpoles.

\begin{tabular}{llrll}
\hline & $\begin{array}{l}\text { Sum of } \\
\text { Source of variation }\end{array}$ & squares & df & \multicolumn{1}{l}{$F$} \\
\hline Predator & 0.684 & 1 & 37.896 & 0.000 \\
Resource & 0.020 & 2 & 0.557 & 0.583 \\
Predator $\times$ resource & 0.291 & 2 & 8.057 & 0.003 \\
Error & 0.325 & 18 & & \\
Time & 0.095 & 1 & 9.032 & 0.008 \\
Time $\times$ predator & 0.025 & 1 & 2.391 & 0.139 \\
Time $\times$ resource & 0.031 & 2 & 1.478 & 0.255 \\
Time $\times$ predator & 0.010 & 2 & 0.471 & 0.632 \\
$\quad \times$ resource & & & & \\
Error & 0.190 & 18 & & \\
\hline
\end{tabular}

Note: Activity levels measured at $4 \mathrm{~h}$ in the presence of a nonlethal predator and measured at $4 \mathrm{~h}$ in the presence of a lethal predator were used as repeated measures.

action effects with predator presence and resource showed that the effect of resource on the activity pattern was similar in the presence or absence of a predator (Table 2). The tadpoles used the bottom habitat more in the presence than in the absence of the predator (Fig. 3, Table 3). The significant resource effects in the second part of the experiment (Table 3) were due to the tadpoles using the bottom less in the phytoplankton treatment (Figs. $3 c, 3 d$ ).
Fig. 2. Proportions (mean $\pm 1 \mathrm{SE}$ ) of observed common frog tadpoles that were active after $4 \mathrm{~h}$ in the absence or presence of a nonlethal $(a)$ or lethal $(b)$ predator $(D$. marginalis) in combined-, benthic-, and phytoplankton-resource treatments.

\section{a)}

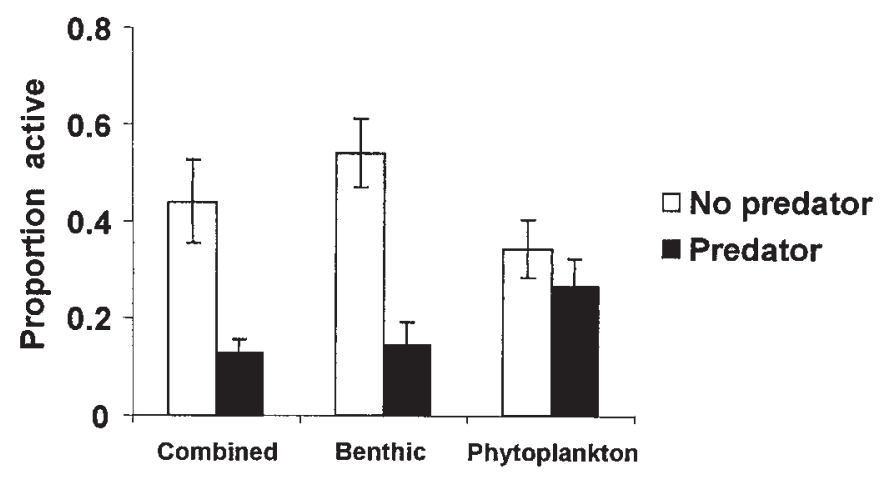

b)

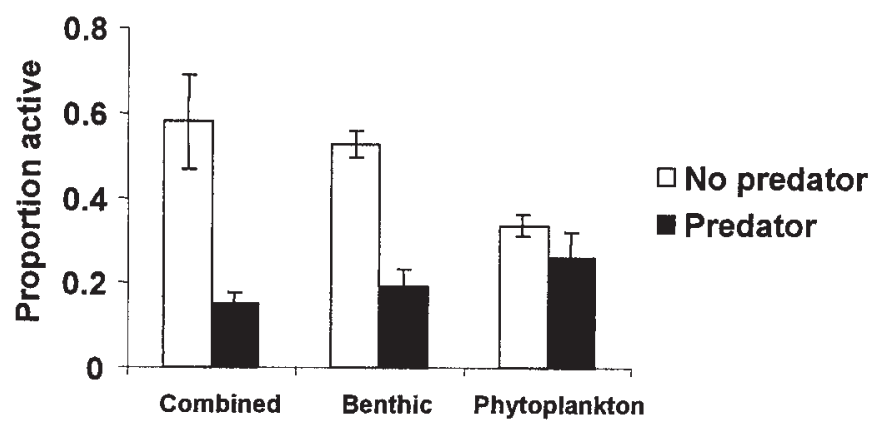

Table 3. ANOVA of the effect of predator and resource (combined, benthic, and phytoplankton) on habitat use by common frog tadpoles after $4 \mathrm{~h}$ and $4 \mathrm{~h}$ after the predator was released.

\begin{tabular}{lcrrr}
\hline Source of variation & $\begin{array}{l}\text { Sum of } \\
\text { squares }\end{array}$ & df & \multicolumn{1}{l}{$F$} & \multicolumn{1}{c}{$P$} \\
\hline After $\mathbf{4}$ h & & & & \\
Predator & 1.879 & 1 & 85.052 & 0.000 \\
Resource & 0.039 & 2 & 0.893 & 0.427 \\
Predator $\times$ resource & 0.002 & 2 & 0.044 & 0.957 \\
Error & 0.398 & 18 & & \\
$\mathbf{4}$ h after predator release & & & & \\
Predator & 0.140 & 1 & 6.984 & 0.017 \\
Resource & 0.296 & 2 & 7.399 & 0.005 \\
Predator $\times$ resource & 0.002 & 2 & 0.057 & 0.944 \\
Error & 0.360 & 18 & & \\
\hline
\end{tabular}

\section{Tadpoles' forage intake}

Tadpoles in the combined- and benthic-resource treatments consumed more food than those in the phytoplankton treatment (Fig. 4; ANOVA, $F_{[2,9]}=10.527, P=0.004$ ).

\section{Predators' activity levels and habitat use}

Predator activity levels did not change among treatments (ANOVA, $F_{[2,9]}=1.057, P=0.391$ ). The predator mainly 
Fig. 3. Proportions of observed common frog tadpoles present in the water column, in the cage, or at the bottom after $4 \mathrm{~h}$ in the absence of a predator (D. marginalis) $(a)$, in the presence of a nonlethal predator $(b)$, after $24 \mathrm{~h}$ in the absence of a predator $(c)$, and after $4 \mathrm{~h}$ in the presence of a lethal predator $(d)$.

\section{$\square$ Water column $\square$ Cage Bottom}

a)

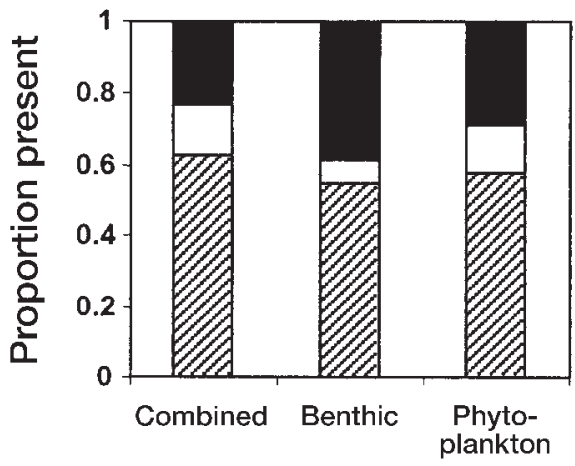

c)

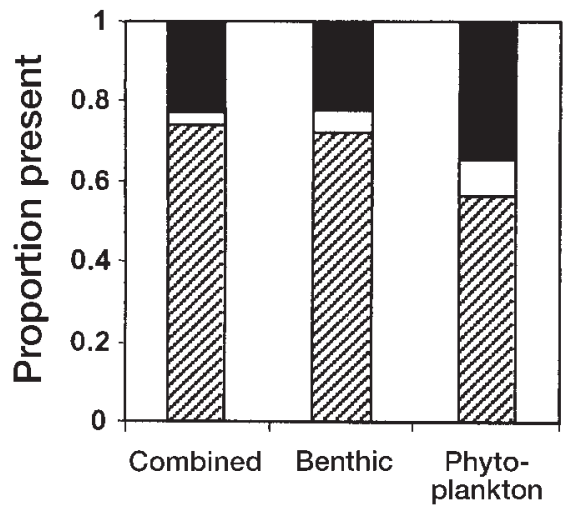

used the bottom of the aquarium $(G=7.14$, df $=2, P<$ $0.001)$, and habitat choice was consistent across resource treatments $(G=2.378$, df $=2, \mathrm{~ns})$.

\section{Discussion}

\section{Resource-dependent activity and predation mortality of tadpoles}

In the presence of the dytiscid predator and the benthic resource, tadpole activity decreased dramatically, whereas in the presence of phytoplankton alone, the predator did not affect tadpole activity. The gut sizes and activity of the tadpoles demonstrate that they adjusted their behavior in relation to both food-resource level and predation risk. In most studies examining the behavior of amphibian larvae that focused on the trade-off between activity and mortality, artificial food resources were used. These studies demonstrated a trade-off between foraging activity and predation mortality that is dependent on food-resource levels (e.g., Anholt and Werner 1995, 1998). The results of our study show that the trade-off between foraging activity and predation mortality changes qualitatively when different types of natural food resources are included. b)

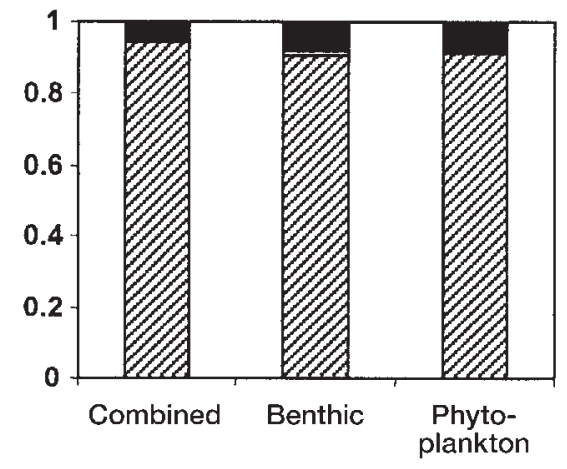

d)

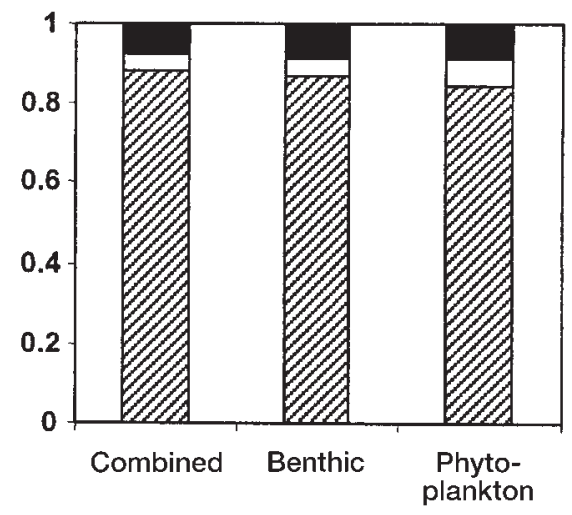

Fig. 4. Lengths (mean $\pm 1 \mathrm{SE}$ ) of common frog tadpole guts after $4 \mathrm{~h}$ in the presence of a nonlethal predator (D. marginalis) in the combined-, benthic-, and phytoplankton-resource treatments.

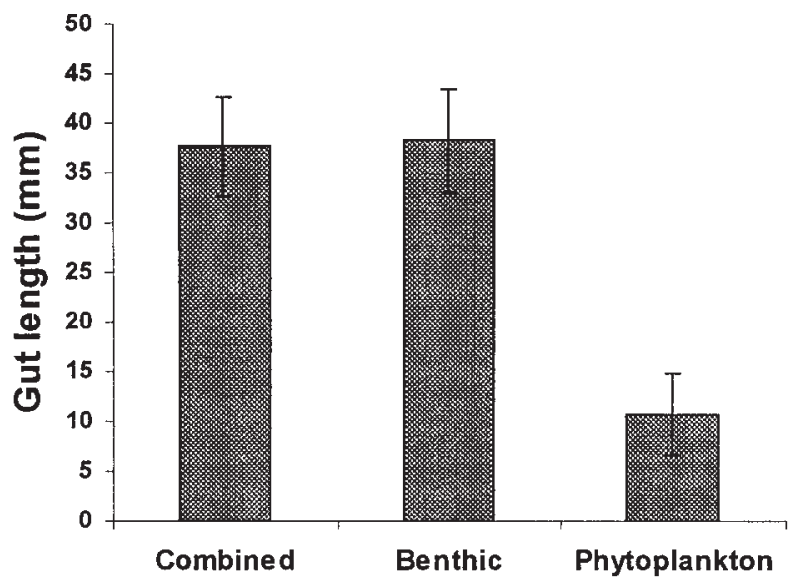

When predation risk increases, individual prey generally reduce their movements and decrease the time spent active, leading to a lower encounter rate with predators and a lower mortality rate than for individuals that are more active (Lima and Dill 1990; Werner and Anholt 1993; Anholt and Werner 
1995, 1998; Leonardsson and Johansson 1997). Activity level is not only a function of predation risk, but is also related to the resource levels experienced by the prey, and animals tend to trade off these two factors (Abrams 1984; Abrams 1991; Werner and Anholt 1993; McNamara and Houston 1994; Anholt and Werner 1995). Many animals under energetic stress accept a greater risk in order to obtain food, as behavioral decisions are based on the levels of risk and gain experienced by individuals at a given moment (reviewed in Lima 1998). Horat and Semlitsch (1994) showed that starved tadpoles increase their activity levels and feeding time under different levels of predation risk. As a consequence, at higher food levels tadpoles are less active and have a lower mortality rate than those raised at lower food levels (Anholt and Werner 1995, 1998).

Gut-length data showed that tadpoles feeding on phytoplankton had a lower food intake than those feeding on benthic resources in the other treatments. This could be due to the fact that either the tadpoles are less efficient on phytoplankton or that the food-resource level was lower in the phytoplankton treatment. In either case, tadpoles consumed less food in the phytoplankton treatment than in the benthic- or combinedresource treatment, and thus, one would predict a higher activity level to compensate for the lower food-intake rate. In fact, both the activity level and predation-mortality rate were higher in the phytoplankton treatment than in the benthicand combined-resource treatments. Previous studies have shown that the common frog is mainly a benthic feeder and is more efficient at scraping than filtering (Viertel 1992), which suggests that forage intake should be greater in habitats with a higher levels of benthic food resources. This was also the case in our study. Furthermore, our study showed that the forage intake of the tadpoles in the benthic- and combinedresource treatments did not differ, indicating that adding the phytoplankton to the benthic food resource did not change the forage-intake rate of the tadpoles. It is also possible that the ingested food did not differ qualitatively between the benthic- and combined-resource treatments, but we never examined the quality of ingested food to verify this.

\section{Feeding and predation risk in anuran communities}

Tadpoles often live in aggregated groups with locally high densities, where resource depletion could be expected (Duellman and Trueb 1986). Density-dependent depletion of resources has been shown to cause an increase tadpole activity levels followed by an increase in predation mortality (Anholt and Werner 1995; Peacor and Werner 1997). A change in activity levels due to lower food-resource levels could also be the mechanism underlying the increase in predation mortality in our experiment. Nevertheless, it is possible that less structural complexity in the phytoplankton treatment could explain the higher predation mortality in this treatment. For example, a study using visually hunting predators showed that the predation rate on amphibian larvae decreased in the presence of structural complexity, owing to constraints on the visibility of prey to the predator (Babbitt and Tanner 1998). However, dytiscid larvae are poor visual hunters and detect their prey mainly through mechanical and chemical cues (Formanowicz 1987), which suggests that their prey-detection rate is governed by encounter rate. Encounter rates will necessarily increase with prey activity (Gerritsen and Strickler 1977). Thus, it is most likely that the predation rate in our experiment was highly influenced by the activity of the prey because the predator did not chase the prey but usually stayed immobile at the bottom of the aquarium and successfully ambushed passing prey.

The prey tended to move to the bottom more in the presence of the predator in our experiment probably because they lose buoyancy when they become inactive. Although the prey sinks into the same habitat as the predator, in natural environments such a response is probably highly adaptive because $(i)$ the encounter frequency decreases when prey activity decreases, and (ii) structurally complex habitats constrain the foraging efficiency of visually hunting predators (Babbitt and Tanner 1998). Furthermore, since the major foraging mode of the common frog is benthic (Viertel 1992), the results of our study and that of Babbitt and Tanner (1998) suggest that a structurally complex environment would provide both food and protection against predators. Potentially, these habitats also restrict the ability of tadpoles to see predators. However, anuran larvae have the ability to detect predators by chemical cues, which commonly cause a strong behavioral response (Kats et al. 1988; Feminella and Hawkins 1994; Laurila 1997; Eklöv 2000). Tadpoles responded strongly to both lethal and nonlethal predators in our experiment by reducing activity, demonstrating that responses to chemical cues were also important in our study. However, if resources are depleted and the use of an alternative food resource such as phytoplankton becomes important, tadpoles would be exposed to other, more visually hunting predators such as odonate larvae. The potential for this was shown in our experiment by tadpoles spending more time in the water column in the phytoplankton treatment than in the other treatments. Thus, if predators with a different foraging mode or habitat specificity are present in the environment, changes in levels of different food resources may lessen the vulnerability of prey to different predators. Therefore, although our experiment showed that common frogs trade off foraging activity against predation risk by changing their activity level, the prediction might change, as tadpoles in ponds are usually exposed to more than one predator at a time. The rate of predation by one predator may be altered because the prey changes its behavior in response to another predator (Peacor and Werner 1997; Eklöv and Werner 2000).

In conclusion, common frogs trade off foraging intake with predation risk by changing their activity according to the type of food resource present. Differences in feeding behavior and efficiency (scraping, filtering) depending on the availability of these food resources explain the variation in activity. The fraction of planktonic and benthic food resources can be variable in ponds and lakes, and therefore has considerable potential to affect the trade-off between forage intake and predation risk. Furthermore, since anuran species differ in their efficiency on different type of food resources, we can expect the trade-off between foraging intake and predation risk for a certain species to also vary when other competitors are present in the environment (Vertiel 1992; L.C. Schiesari and E.E. Werner, unpublished data). To better understand the mechanisms that control foraging decisions made under predation risk by anuran larvae, we need more 
studies that evaluate how different food resources affect the trade-off between foraging intake and predation risk, and how structural complexity interacts with behavioral decisions.

\section{Acknowledgements}

We thank Peter Abrams, Brad Anholt, Joakim Hjelm, and Frank Johansson for helpful comments on the manuscript. The research was partly funded by the Department of Biology, Umeå University, for completion of a Master's degree by Charlotta Halvarsson and by a grant from the Swedish Council for Forestry and Agricultural Research to Peter Eklöv.

\section{References}

Abrams, P.A. 1984. Foraging time optimization and interactions in food webs. Am. Nat. 124: 80-96.

Abrams, P.A. 1991. Life history and the relationship between food availability and foraging effort. Ecology, 72: 1242-1252.

Abrams, P.A. 1993. Why predation rates should not be proportional to predator density. Ecology, 74: 726-733.

Anholt, B.R., and Werner, E.E. 1995. Interaction between food availability and predation mortality mediated by adaptive behaviour. Ecology, 76: 2230-2234.

Anholt, B.R., and Werner, E.E. 1998. Predictable changes in predation mortality as a consequence of changes in food availability and predation risk. Evol. Ecol. 12: 729-738.

Babbitt, K.J., and Tanner, G.W. 1998. Effects of cover and predator size on survival and development of Rana utricularia tadpoles. Oecologia, 114: 258-262.

Duellman, W.E., and Trueb, L. 1986. Biology of amphibians. McGraw-Hill, New York.

Eklöv, P. 2000. Chemical cues from multiple predator-prey interactions induce changes in behavior and growth of anuran larvae. Oecologia. In press.

Eklöv, P., and Werner, E.E. 2000. Multiple predator effects on sizedependent behaviour and mortality of two species of anuran larvae. Oikos, 88: 250-258.

Feminella, J.W., and Hawkins, C.P. 1994. Tailed frog tadpoles differentially alter their feeding behaviour in response to nonvisual cues from four predators. J. North Am. Benthol. Soc. 13: 310-320.

Formanowicz, D.R., Jr. 1987. Foraging tactics of Dytiscus verticalis larvae (Coleoptera: Dytiscidae): prey detection, reactive distance and predator size. J. Kans. Entomol. Soc. 60: 9299.

Gerritsen, J., and Strickler, J.R. 1977. Encounter probabilities and community structure in zooplankton: a mathematical model. J. Fish. Res. Board Can. 34: 73-82.

Horat, P., and Semlitsch, R.D. 1994. Effects of predation risk and hunger on the behaviour of two species of tadpoles. Behav. Ecol. Sociobiol. 34: 393-401.
Kats, L.B., Petranka, J.W., and Sih, A. 1988. Antipredator defences and the persistence of amphibian larvae with fishes. Ecology, 69: $1865-1870$.

Kupferberg, S.J. 1997a. Facilitation of periphyton production by tadpole grazing: functional differences between species. Freshwater Biol. 37: 427-439.

Kupferberg, S.J. 1997b. The role of larval diet in anuran metamorphosis. Am. Zool. 37: 146-159.

Laurila, A. 1997. Breeding habitat choice and larval ecology in two anurans. Ph.D. Dissertation, University of Helsinki, Finland.

Leonardsson, K., and Johansson, F. 1997. Optimum search speed and activity: a dynamic game in a three-link trophic system. J. Evol. Biol. 10: 703-729.

Lima, S.L. 1998. Stress and decision making under the risk of predation: recent development from behavior, reproductive and ecological perspectives. Adv. Study Behav. 27: 215-290.

Lima, S.L., and Dill, L.M. 1990. Behavioral decisions made under the risk of predation: a review and prospectus. Can. J. Zool. 68: 619-640.

McNamara, J.M., and Houston, A.I. 1987. Starvation and predation as factors limiting population size. Ecology, 68: 1515-1519.

McNamara, J.M., and Houston, A.I. 1994. The effect of a change in foraging options on intake rate and predation rate. Am. Nat. 144: $978-1000$.

Milinski, M., and Heller, R. 1978. Influence of predator on the optimal foraging behaviour of sticklebacks (Gasterosteus aculeatus L.). Nature (Lond.), 275: 642-644.

Peacor, S.D., and Werner, E.E. 1997. Trait-mediated indirect interactions in a simple aquatic food web. Ecology, 78: 1146-1156.

Peckarsky, B.L., and Penton, M.A. 1989. Mechanisms of prey selection by stream-dwelling stoneflies. Ecology, 70: 1203-1218.

Sanderson, S.L., and Kupferberg, S.J. 1999. Development and evolution of aquatic larval feeding mechanisms. In The origin and evolution of larval forms. Edited by B.K. Hall and M.H. Wake. Academic press. pp. 301-377.

Wassersug, R.J. 1972. The mechanism of ultraplanktonic entrapment in anuran larvae. J. Morphol. 137: 279-288.

Werner, E.E. 1992. Individual behavior and higher-order species interactions. Am. Nat. 140: S5-S32.

Werner, E.E., and Anholt, B.R. 1993. Ecological consequences of the trade-off between growth and mortality rates mediated by foraging activity. Am. Nat. 142: 242-272.

Werner, E.E., and Anholt, B.R. 1996. Predator-induced behavioral indirect effects: consequences to competitive interactions in anuran larvae. Ecology, 77: 157-169.

Werner, E.E., and Gilliam, J.F. 1984. The ontogenetic niche and species interactions in size-structured populations. Annu. Rev. Ecol. Syst. 15: 393-425.

Viertel, B. 1992. Functional response of suspension feeding anuran larvae to different particle sizes at low concentrations (Amphibia). Hydrobiologia, 234: 151-173. 